\title{
Experimental study of rock mass characteristics for Kariba Power Station based on the acoustic and optical logging technology
}

\author{
Liming Zhou *, Fagang Wang, Rong Luo, Guoqiang Xiao \\ Key Laboratory of Geotechnical Mechanics and Engineering of the Ministry of Water Resources \\ Changjiang River Scientific Research Institute \\ Wuhan, China \\ brian5396@126.com
}

\begin{abstract}
In order to estimate the geological and structural rock mass characteristics in the site of upper course cofferdam of water inlet, gate shaft of water inlet and Sd1 district in south bank expansion project of Kariba south power station, Some experimental investigations were done based on the acoustic and optical logging technology. BH4\#, BH4-1\#, BH5\#, BH12\# is the identity for each test drill hole, and the parameters of thickness of covering layer, weathering degree of bedrock, fissures development degree, wave velocity of rock mass were got by single hole acoustic wave tests and optical drill hole television recordings.
\end{abstract}

Keywords—kariba power station; acoustic logging;optical logging; rock mass structure

\section{INTRODUCTION}

Kariba power station straddles at the mid-section of the Zambezi River on the borders of Zimbabwe and Zambia. The main structures of south bank expansion project consist of water inlet, diversion tunnel, underground powerhouse, tail water surge-chamber, tail water tunnel, tail water outlet, main transformer and switch station. On both sides of the gorge, the peaks of lofty mountains are 183 meters to 488 meters above the water level and the slope angles of natural slopes are generally between 30 and 40 . The artificial slopes in the engineering positions are very steep that with slope angles between 65 and 75, and the heights of these artificial slopes, such as highway slopes and water outlet slopes, are 15 to 30 meters ordinarily. Some slopes, such as south bank slopes, have been treated by slurry masonry paving. Some slopes such as tail water outlets slopes on both banks have been built concrete retaining wall. And the highway slopes that located the upside of the tail water tunnel on the south bank are reinforced by anchor rope in addition to slurry masonry paving. The river valley is relatively wide and the watercourse is straight at the dam site.

In order to estimate the geological and structural conditions in the site of upper course cofferdam of water inlet, gate shaft of water inlet and Sd01 district in south bank expansion project

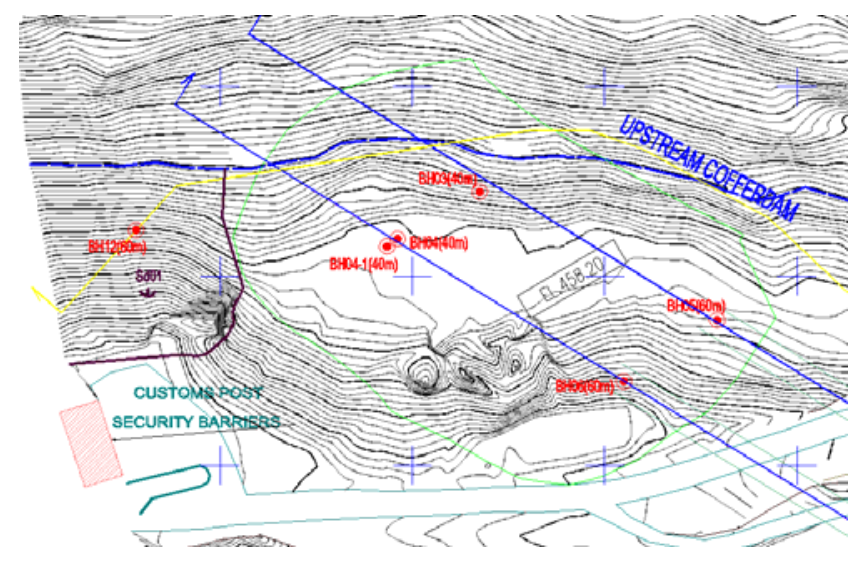

Fig. 1. Arrangement plan for test drill holes.

of Kariba Power Station, we did single hole acoustic wave tests and optical drill hole television recordings in designated area. The identity of each test drill hole is BH5\#, BH12\#, BH4\#, BH4-1\# respectively, and the depth of these holes are $60 \mathrm{~m}$, $60 \mathrm{~m}, 40 \mathrm{~m}, 40 \mathrm{~m}$ according to priority. The arrangement plan of test drill holes is showed in Fig. 1.

\section{ENGINEERING GeOLOGICAL CONDITONS}

In the site of headrace open channel, it's a platform formed by abandoned dreg with a width from 10 meters to 30 meters and a height from11.5 meters to 12 meters based on the stratigraphy of drill hole in BH03\# and BH04\#. The natural slope angle of platform slope closed to reservoir is from 35 to 45 , and 29 to 43 for the south slope besides in certain areas the slope rise steeply where the angle is up to 70 . The natural slope angle is from 28 to 45 in the site of tunnel inlet, and the differential height of excavating is up 55 meters from the bottom of tunnel. According to the stratigraphy acquired in BH05\#, the thickness of covering layer is between 7 meters and 12 meters in the site of open channel and water inlet. The thickness of intensely weathered mica gneiss is between 12 meters and 15 meters and weathered quartzite is below. Covering layer mainly consists of colluvial deposits and artificial accumulated rubbles that with looseness of structure. 
Headrace open channel is founded on the weathered rock block and part located on the intensely weathered rock and it's necessary to reinforce the foundation. The slope rock in the south of open channel is made up of three parts: artificial accumulated rubbles with height of 5 to10 meters, intensely weathered quartz biotite gneiss with height of 15 to24 meters and weathered quartzite on the foot of slope. There are a series of cracks (NE30 ${ }^{\circ} \mathrm{NW} \angle 55^{\circ}(\mathrm{L} 29)$, NW298 $\sim 335^{\circ} \mathrm{SW} \angle 82^{\circ} \sim$ $88^{\circ}$ (L41, L42, L43) in the rock mass of slope, which intersect the fissures and joints of quartz biotite gneiss. These situations are prone to form unstable blocks. The slope rock in the north open channel consists of artificial accumulated rubbles with height of 10 to12 meters and quartz intensely weathered biotite gneiss below (it's completely- intensely weathered mica gneiss in upstream side). Gneiss is softened due to dousing for many years, so supporting and plate retaining should be constructed in time when excavating. There are loosened rocks of Sd1 district in upper course of the excavation of water inlet, so it is necessary to take engineering treatment steps to protect this district. Furthermore, groundwater is rich because open channel immediately adjacent to the reservoir, and permeability of covering layers are greater than $11 \mathrm{Lu}$, permeability of weathering rocks are between 4.4 and $10.4 \mathrm{Lu}$, so the drainage design is necessary.

The layers are artificial accumulated rubbles, intensely weathered quartz biotite gneiss, quartzite, weathering quartzite from top to bottom in site of water inlet of tunnel. The cracks are mainly with steep dip, such as L04 $\left(\mathrm{NE67}{ }^{\circ} \mathrm{NW} \angle 82^{\circ}\right)$ and L05(NE70 ${ }^{\circ} \mathrm{NW} \angle 72^{\circ}$ ), and there are some cracks with lowangle dip, such as $\mathrm{L} 3\left(\mathrm{NE} 35^{\circ} \mathrm{NW} \angle 35^{\circ}\right)$. The cracks intersect with each other to form many unstable blocks, and these unstable blocks tend to collapse and slip in the process of construction. Gate shaft of tunnel is founded on the intensely weathered quartz biotite gneiss that ultimate bearing capacity of foundation is below $1 \mathrm{MPa}$. The ratio of slope excavation is suggested as follows: 1:1 to 1:25 for covering layer, 1:0.75 to 1:1 for intensely weathered rock mass, 1:0.5 to $1: 0.75$ for weathered rock mass.

\section{THEORY AND METHOD}

\section{A. Single Hole Acoustic Wave Test}

One sending double receiving device is used in single hole acoustic wave test. One transmission energy converter and two receiving energy converters make up probe head. Pulse signal source and recording device make up ground portion. The theory of this test is refraction axiom of wave when transmission energy converter sends pulsed ultrasonic signal, refraction occurs at the interface between water and rock mass, and received by two receiving energy converters. The first arrival time of longitudinal wave that converters receive and the distance from one receiving energy converter to another are used to calculate the velocity of longitudinal wave of rock mass. In the process of test, water is coupling, sampling at $0.2 \mathrm{~m}$ intervals, and interval is adjustable to assure the sampling

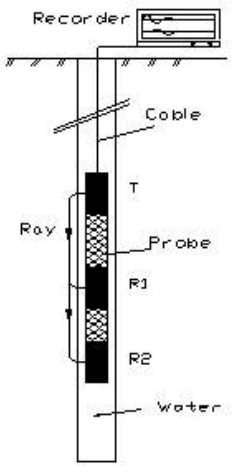

Fig. 2. Schematic diagram of single hole acoustic wave test.

interval is short. Fig. 2 is the schematic diagram of single hole acoustic wave test.

The first arrival time of longitudinal wave that two converters receive $(t 1, t 2)$ are used to calculate the wave velocity $\left(\mathrm{V}_{\mathrm{p}}\right)$ of the detect point.

$$
V_{p}=L /\left(t_{2}-t_{1}\right)
$$

Where $\mathrm{L}$ is the distance from one receiving energy converter to the another one. The velocity-depth curve is plotted used the test value. The rock mechanic characters can be presumed based on the test, the joints and cracks with lowangle dip are sensitive to this test especially.

\section{B. Optical Drill Hole Television Recording}

Optical drill hole television system can do recording in both air and clear water, and the wall of a well can directional unfold to a high resolution image. The operating principle of drill hole television is that wall rock characters around the well section (A'B'C'D') are reflected to the high definition digit camera by a round counter-top conoscope (O’O’), which is in the probe head of digit drill hole television system and directly below the camera, as shown in Fig. 3(a). The imaging of the wall process in the camera is concentric ring that is shown in Fig. 3(b). Base on the difference angles that recorded by digital compass and the depth information recorded by depth counter at the moment of imaging, the ichnography of round wall (A'B'C'D') can be spread out. The top-down ichnography of wall is shown by splicing the sections in depth and original image is shown by curling the ichnography. The images and videos are stored in computer directly, the characters of drill hole can be analyzed by analyzing software.

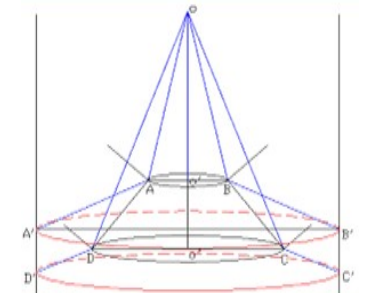

(a)

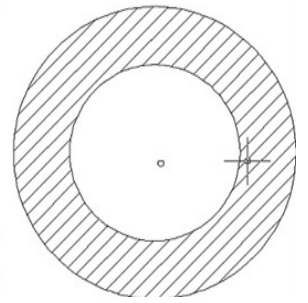

(b)
Fig. 3. Schematic diagram of imaging principle. 


\section{TEST REsUlT}

\section{A. Results of Single Hole Acoustic Wave Test}

The velocity-depth curve is plotted by the use of the value of velocity that calculated with the test data of single hole acoustic wave. The test depth of $\mathrm{BH} 4-1 \#$ is $20.8 \mathrm{~m}$ and the velocities in this hole are all blow 1500 meters per second that show the walls of hole are cracked. So velocity-depth curve and cartogram of BH4-1\# is not plot. Fig. 4 is drawn as the typical curve of the velocity and depth.

The statistic results of wave velocities are shown in Fig. 5 in the test districts.

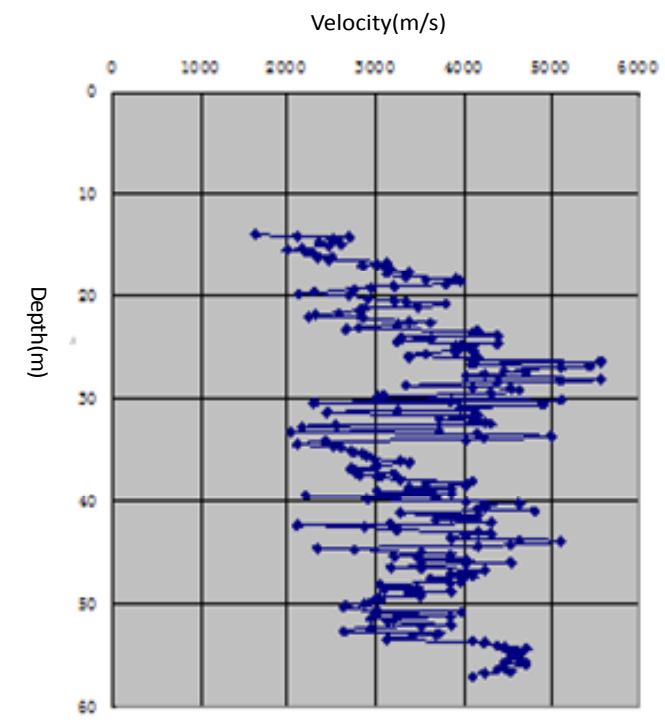

Fig. 4. Schematic diagram of imaging principle.
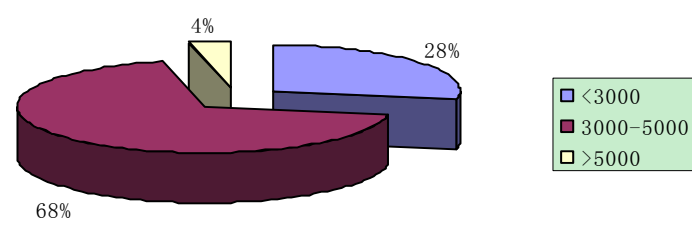
ㅁ $>5000$

(a) $\mathrm{BH} 5 \#$
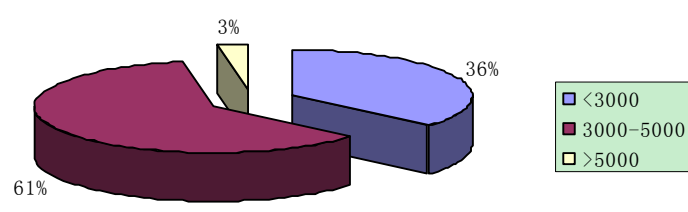

(b)BH12\#

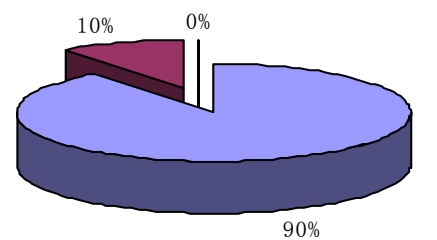

(c)BH4\#

Fig. 5. Cartogram of single hole wave velocities.
Based on the acoustic wave test in BH5\# that is in site of gate shaft of water inlet and $\mathrm{BH} 12 \#$ that is in site of Sd01 district, the wave velocities are between 3000 meters per second and 5000 meters per second, and the average velocity is 3500 meters per second. The wave velocities of rock mass in low-velocity zone are between 1700 and 3000 meters per second and the thickness of covering layer is about 26 meters. The average velocity is 3200 meters per second in Sd01 district and the thickness of covering layer is 21 meters.

Based on the acoustic wave test in BH4\# and BH4-1\# that are in site of upper course cofferdam of water inlet, the velocities in BH4-1\# are all blow 1500 meters per second and the test depth of BH4-1\# is $20.8 \mathrm{~m}$, that show the walls of hole are cracked. The average velocity is 2000 meters per second in BH4\#, and the velocities are blow 3000 meters per second mostly. The velocities are 1500 and 2000 meters per second in low-velocity rock mass zone. The thickness of covering layer in the district of upper course cofferdam of water inlet is above 30 meters.

\section{B. Results of Optical Drill Hole Television Recording}

The results of the typical optical drill hole television record are shown in Fig. 6. The test depth is 51.9 meters and the length of casing is 6.8 meters in BH5\# drill hole where the groundwater level is 11.7 meters. In BH4\#, the test depth is 26.7 meters and the length of casing is 8.3 meters, the water level is 14.1 meters. Because the walls of hole are cracked and more cement is used to render dado and clear the bottom of the hole, the surfaces of the wall of hole are overlaid with cement. So the results of this hole are not used to do statistics. The test depth is 16.5 meters in BH4-1\#, the casing is 0.35 meters long and the water level is 14 meters. There is artificial accumulated body from ground to a depth of 8 meters where the walls of hole are cracked, and the main materials are rubble and intensely weathered gneiss. It is bedrock blow 8.7 meters.
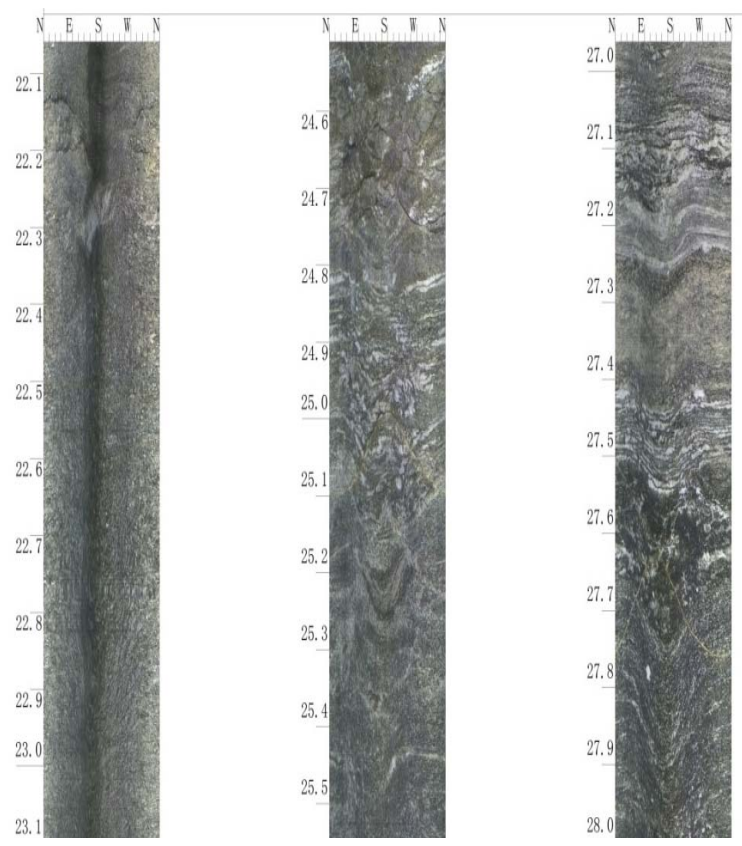

Fig. 6. The typical optical drill hole television record. 


\section{CONCLUSIONS}

The water level in the site of gate shaft of water inlet is about 13.1 meters. The hole wall is complete, and the wave velocity of rock mass is relatively high, the average wave velocity is about $3500 \mathrm{~m} / \mathrm{s}$. There are fissures in local area and the main fissures amount to 11 . The thickness of covering layer is about 26 meters.

The water level in the site of Sd01 is about 11.7 meters. The average wave velocity of rock mass in this place is about 3200 meters per second. The total main fissures add up to 12, and there are some unfilled cavities in local area. The thickness of covering layer is about 21 meters.

The water level in the site of upper course cofferdam of water inlet is about 14.1 16.5 meters. The rock mass in this district is relatively fragmental, which is intensely weathered rock. The wave velocity is relatively slow, the average velocity is 2000 meters per second. The thickness of covering layer is above 30 meters including rock filled that is about 8.5 meters.

\section{ACKNOWLEDGMENT}

This research is funded by National Natural Science Foundation of China (Grant No.41202223 and Grant No.51409013).

\section{REFERENCES}

[1] Zhou Liming, Xiao Guoqiang,and Yin Jianmin "Measurement and analysis on the thickness of power tunnels loosened zone for Bakun Hydropower Station,” Proceedings of the 2th International Conference on Environment and Engineering Geophysical. Wuhan, China, vol.1,pp. 196-200, June 2006 .

[2] Deng Maowu, “Application of Sonic Method in Determining Surrounding Rock Loosening Belt of Underground Cave,” GX Water Resources\& Hydropower Engineering, vol. 3, pp. 7-10, March 2005.

[3] Kong Guangsheng, "The application of borehole acoustic televiewer logging results to the classification of rock weathering degrees," Geophysical \& Geochemical Exploration, vol.29, pp. 367-373, August 2005. 